Article

\title{
Effects of Double Diffusion Convection on Third Grade Nanofluid through a Curved Compliant Peristaltic Channel
}

\author{
Hanan Alolaiyan ${ }^{1}\left(\mathbb{D}\right.$, Arshad Riaz $^{2, *(\mathbb{D}}$, Abdul Razaq $\left.^{2}{ }^{(}\right)$, Neelam Saleem ${ }^{3}$, Ahmed Zeeshan $^{4}(\mathbb{D})$ \\ and Muhammad Mubashir Bhatti ${ }^{5}$ \\ 1 Department of Mathematics, King Saud University, Riyadh 11451, Saudi Arabia; holayan@ksu.edu.sa \\ 2 Department of Mathematics, Division of Science and Technology, University of Education, Lahore 54770, \\ Pakistan; abdul.razaq@ue.edu.pk \\ 3 Department of Mathematics, University of Sargodha, Sargodha 40100, Pakistan; neelamsaleem34@gmail.com \\ 4 Department of Mathematics \& Statistics, Faculty of Basic and Applied Sciences (FBAS), International Islamic \\ University (IIUI), Islamabad 44000, Pakistan; ahmad.zeeshan@iiu.edu.pk \\ 5 College of Mathematics and Systems Science, Shandong University of Science and Technology, \\ Qingdao 266590, China; mmbhatti@sdust.edu.cn \\ * Correspondence: arshad-riaz@ue.edu.pk
}

Received: 22 November 2019; Accepted: 26 January 2020; Published: 8 February 2020

\begin{abstract}
Nanofluids are potential heat transfer fluids with improved thermophysical properties and heat transfer performance. Double diffusion convection plays an important role in natural processes and technical applications. The effect of double convection by diffusion is not limited to oceanography, but is also evident in geology, astrophysics, and metallurgy. For such a vital role of such factors in applications, the authors have presented the analytical solutions of pumping flow of third-grade nanofluid and described the effects of double diffusion convection through a compliant curved channel. The model used for the third-grade nanofluid includes the presence of Brownian motion and thermophoresis. Additionally, thermal energy expressions suggest regular diffusion and cross-diffusion terms. The governing equations have been constructed for incompressible laminar flow of the non-Newtonian nanofluid along with the assumption of long wavelength. The obtained analytical expressions for velocity, temperature, and nanoparticle concentration have been sketched for various considerable parameters. The effects of regular buoyancy ratio, buoyancy parameter, modified Dufour parameter, and Dufour-solutal Lewis number have been analyzed along with wall properties and pumping characteristics. This study concludes that fluid becomes hotter with increase in regular buoyancy ratio and a modified Dufour parameter, but a decrease in temperature is observed for the buoyancy parameter. Moreover, the solutal concentration is behaving inversely against the Defour-Solutal Lewis number.
\end{abstract}

Keywords: double diffusion; nanofluid; curved channel; peristaltic pumping; compliant walls; analytical solutions; third grade fluid model

\section{Introduction}

Nanofluid has served in a number of engineering applications, for example, porous materials [1,2], fuel-cell industry [3], etc. due to its significant increase in the heat-transfer rate compared to conventional engineered fluid [4]. Nanofluids are another class of fluids made by scattering at the nanometer scale materials (nanoparticles, nanofibers, nanotubes, nanowires, nanorods, nanosheets, or nanobeads) in base fluids. As it were, nanofluids are nanoscale colloidal suspensions containing dense nanomaterial. They are two-stage frameworks with one stage (solid stage) into another (fluid 
stage). It was discovered that nanofluids have improved thermophysical properties, for example, thermal conductivity, heat-diffusivity, thickness, and convective warmth move coefficients contrasted with those of base fluids, like oil or water. It has indicated incredible potential applications in numerous zones. Some investigations on nanofluid can be cited in [5-9]. Most of the human vessels are flexible in nature and the peristaltic flows exhibit such kind of geometries. The flows of such types are very useful in industry, engineering and medical. These flows have also immense applications in curing cancer cells. Abd Elnaby and Haroun [10] have studied the influence of conformal wall properties on peristaltic movement in a two-dimensional channel and produced the conclusion that the reverse pumping rate increases by rising the wall damping and reduces under the increasing magnitude of the wall elasticity as well as tension, which differs from the model used by Mittra and Prasad [11] and Srivastava and Srivastava [12]. Muthu et al. [13] analyzed the peristaltic movement of a micropolar fluid in circular cylindrical tubes with elastic wall properties. They suggested from the obtained measurement that viscous damping is affecting the mean flow reversal over the elastic surface. Nadeem et al. [14] obtained an analytical solution for pumping transport of Williamson nanofluid through a curved channel with compliant walls and offered the readings under the variation of curvature of the enclosure and heat transfer coefficient. Although a large number of studies on the peristaltic flow of conventional fluids are available, only a few articles have been reported on the peristaltic flow of nanofluids [15-18]. In this regard, Akbar et al. [19] investigated the copper nanoparticles impinging on a curved channel with compliant walls and peristalsis. They acquired analytical solutions for temperature distribution and nanoparticle concentration. Due to the importance of the effects Soret (thermal diffusion) and Dufour (diffusion-Thermo), many investigators have been studied which can be found in [20-22].

Collective forced, free convection (mixed convection stream) is occurred in large number of engineering and industrial processes, like solar central receivers attached to the wind potentials, cooling of electronic equipment through fans and nuclear reactors during emergency shutdown and heat transfers kept in lower-velocity surroundings. Heat and mass transfers accompanying effect on each other also produce a cross-diffusion influence. The temperature difference generates mass transfer which is known as Soret effect, on the other hand, the Dufour effect comes from the heat transfer produced by the concentration gradient. Due to wide range of aplications, peristaltic transport of Jeffrey fluid with double diffusion convection for nanofluids has been analyzed by Akram et al. [23] in the presence of a tilted magnetic field. Exact solutions are obtained for the breaking field of nanoparticles, the concentration field, the temperature field, the flow functions, the pressure gradient and the pressure increase with respect to the axial and transverse coordinates on the length restrictions of longwave and low Reynolds number. Akbar and Habib [24] have discussed the peristaltic flow induced by natural double-diffusive convection to achieve a nanofluid magnetic field analysis in an asymmetric porous channel and obtained solutions in a series of five coupled equations.

The feature of compliant wall in peristaltic flows is a key tool for governing muscle tension. This physical phenomenon has been revealed mathematically by a system of equations which are linked to compliant walls displacement [25,26]. Srinivasvas and Kothandapani [27] have investigated the transfer of heat and mass effects on wavy flow through a porous region experiencing compliant walls. Batti et al. [28] have introduced the wavy phenomenon of Jeffrey fluid in a non-uniform rectangular enclosure with the effects of variable magnetic field. They proposed the attributes of non-uniformity of channel on the flow with the incorporation of lubrication theory and obtained the exact solutions. Bhatt et al. [29] have published the hall current factor on peristaltic analysis of heated particle-fluid combined flow with compliant wall properties through numerical treatment. It is to be mentioned here that the analysis of double diffusion mixed convection for a wavy mechanism of viscoelastic nanofluid in a curved structured geometry has not been yet investigated.

Keeping in mind the importance of above-discussed literature and wide range of applications of mixed convection phenomenon with nanoparticles in peristaltic flows, the authors converted their attention to exploring the theoretical effects of double diffusion over peristaltic flow of nanofluid having third-grade fluid as a base fluid through a curved channel along with wall properties. 
Most probably, this study will be the best direction to efficiently use the achieved data in experimental side. The equations of continuity, momentum, energy, and nanoparticle concentration have been modeled through some suitable physical conditions like low values of wavenumber and the Reynolds number. The observing equations are then solved analytically by using a perturbation method. The results are manipulated graphically and discussed in detail. The parameters affecting the phenomenon have been described individually.

\section{Mathematical Modeling}

The problem is to contemplate the effects of double diffusion on the peristaltic transport of an impermeable third-grade fluid in a compliant curved channel having radius $R$ and uniform width $2 d$ bent in the form around the curve with central point having the corresponding components $u$ and $v$ in above-mentioned sides (see Figure 1a). The walls have been structured to become wavy along the flow and have the mathematical expression as described below. The operating equations for the obstacle are [18]

$$
\begin{gathered}
\nabla \cdot V=0 \\
\rho_{f}\left(\frac{\partial v}{\partial t}+V \cdot \nabla V\right)=-\nabla p+\mu \nabla \cdot S \\
+\left(\varphi \rho_{p}+(1-\varphi) \rho_{f}\left(1-\beta_{t}\left(T-T_{1}\right)-\beta_{c}\left(C-C_{1}\right)\right)\right) g \\
(\rho c)_{f}\left[\frac{\partial T}{\partial t}+V \cdot \nabla T\right]=K \nabla^{2} T+(\rho c)_{p}\left(D_{b} \nabla \varphi \cdot \nabla T+\frac{D_{t}}{T_{1}}(\nabla T \cdot \nabla T)\right) \\
+(\rho c)_{f} D_{t c} \nabla^{2} C \\
\frac{\partial C}{\partial t}+V \cdot \nabla C=D_{s} \nabla^{2} C+D_{c t} \nabla^{2} T, \\
\left.\frac{\partial \varphi}{\partial t}+V \cdot \nabla\right] \varphi=D_{b} \nabla^{2} \varphi+\left(\frac{D_{t}}{T_{1}}\right) \nabla^{2} T,
\end{gathered}
$$

where $\rho_{f}$ and $\rho_{p}$ suggest the fluid and particles density in order; $c$ stands for volumetric coefficient; $V$ implies the velocity column; $f$ gives the forcing factor; $P$ delivers the pressure term; $e$ represents the nanoparticles strength; $T_{0}, C_{0}$, and $\varphi_{0}$ describe the contextual representatives of $T, C$, and $\varphi$ at lower wall, respectively; and $T_{1}, C_{1}$, and $\varphi_{1}$ are the correspondent at the upper wall; $D_{b}$ depicts the Brownian diffusion factor; $D_{t}$ the thermophoretic diffusion coefficient; $\beta_{t}$ shows the volumetric volume expansion coefficient for the liquid; $\beta_{c}$ is the cognate solutal coefficient; $D_{c t}$ represents the soret diffusivity; $D_{s}$ reveals the solutal diffusivity; $D_{t c}$ directs the Dufer diffusivity; and $S$ sweeps the fluid model tensor. We use the following dimensional quantities

$$
\begin{gathered}
x^{*}=\frac{x}{\lambda}, r_{1}^{*}=\frac{r_{1}}{d_{1}}, t^{*}=\frac{c t}{\lambda}, w_{1}^{*}=\frac{w_{1}}{d_{1}}, k^{*}=\frac{R_{1}^{*}}{d_{1}}, \\
p^{*}=\frac{d_{1}^{2} p}{c \lambda \mu}, S_{i j}^{*}=\frac{d_{1} S_{i j}}{c \mu}, \theta=\frac{T-T_{0}}{T_{1}-T_{0}}, \phi=\frac{C-C_{0}}{C_{1}-C_{0}}, \\
\gamma=\frac{\varphi-\varphi_{0}}{\varphi_{1}-\varphi_{0}}, \quad N_{c}=\frac{\beta_{c} C_{0}}{\beta_{t} T_{0}}, \quad N_{r_{1}}=\frac{\rho_{p}-\rho_{f}}{\left(1-\varphi_{0}\right) \rho_{f} \beta_{t} T_{0}}, \quad \tau=\frac{(\rho c)_{p}}{(\rho c)_{f}},
\end{gathered}
$$




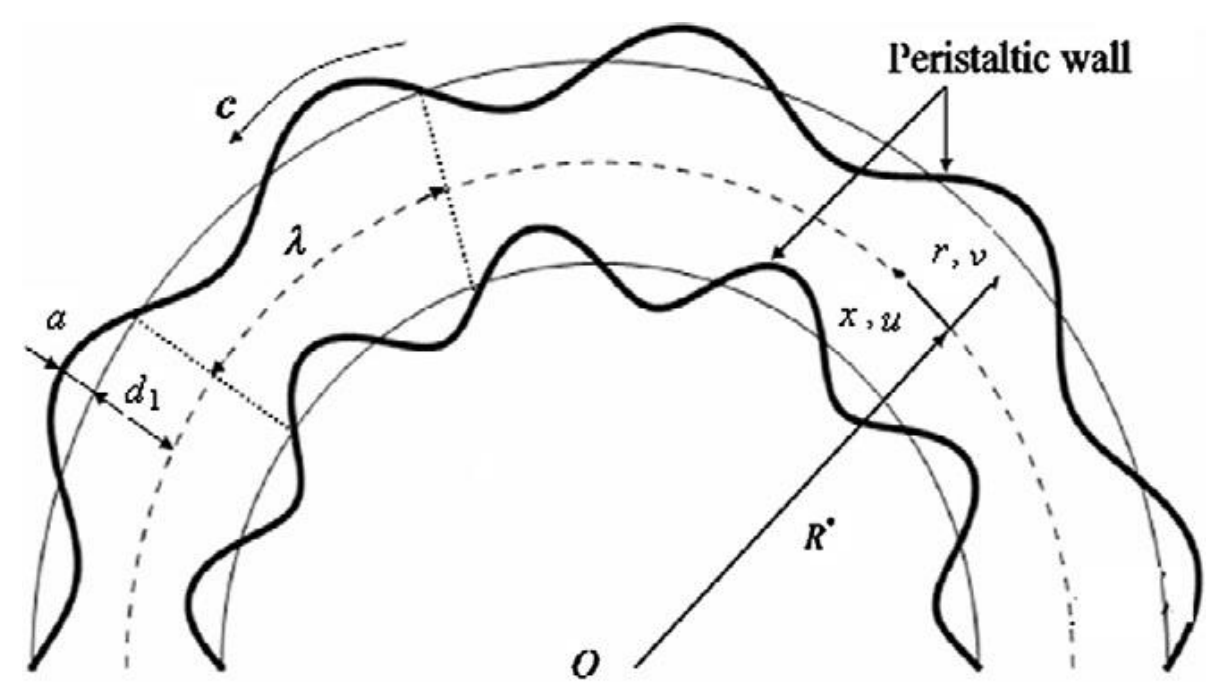

(a)

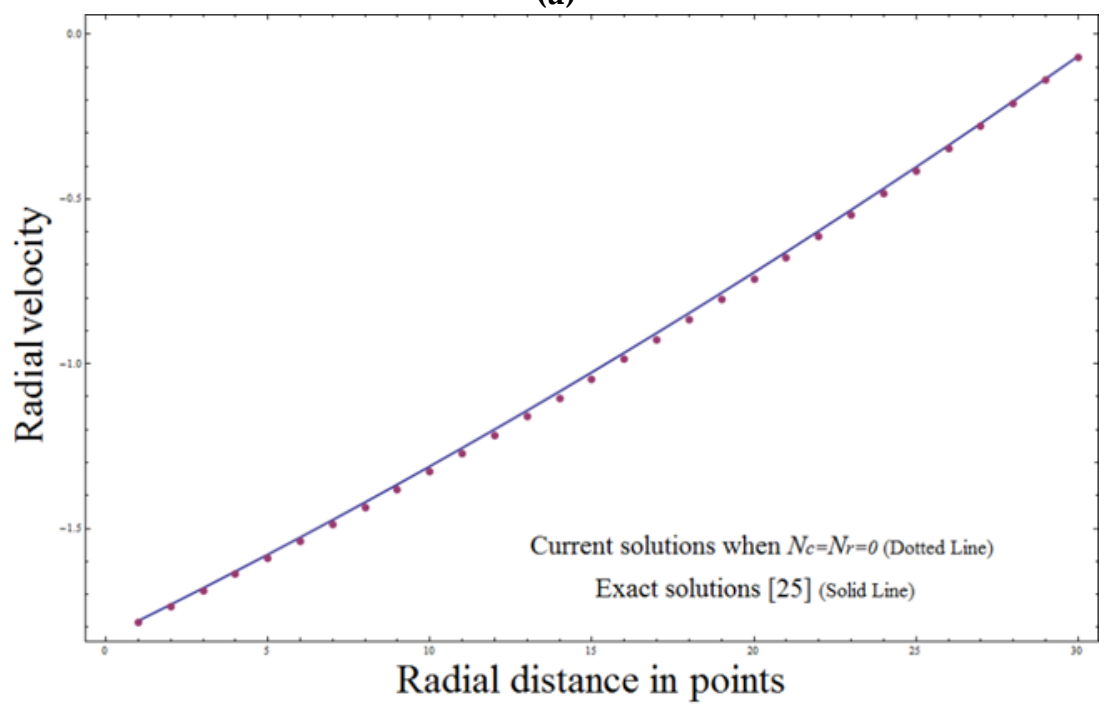

(b)

Figure 1. (a) Geometry of the problem. (b) Comparison of current work with literature [25].

The new discovered parameters like $L_{d}, N_{b}, N_{c}, N_{d}, N_{r 1}$ and $N_{t}$ take place for a Dufour Lewis number, a Brownian motion parameter, the regular double-diffusive buoyancy ratio, a modified Dufour parameter, the nanofluid buoyancy ratio, and the thermophoresis parameter, accordingly. According to the mechanism of flow, the velocity field is supposed as $\mathbf{V}=(v, u)$. After using above defined parameters and applying the conditions of low Reynolds number and long wavelength, the Equations (1)-(5) get the next coming form

$$
\begin{gathered}
-\frac{l}{r_{1}+k_{1}} \frac{\partial p}{\partial x}+\frac{1}{r_{1}+k_{1}} \frac{\partial}{\partial r_{1}}\left[\left(r_{1}+k_{1}\right)^{2} S_{r_{1} x}\right]+N_{c} \gamma+\theta-N_{r_{1}} \phi=0 \\
{\left[\frac{\partial^{2} \theta}{\partial r_{1}{ }^{2}}+\frac{1}{r_{1}+k_{1}} \frac{\partial \theta}{\partial r_{1}}+N_{b} \frac{\partial \phi}{\partial r_{1}} \frac{\partial \theta}{\partial r_{1}}+N_{t}\left(\frac{\partial \theta}{\partial r_{1}}\right)^{2}+N_{d}\left[\frac{\partial \gamma}{\partial r_{1}}+\frac{1}{r_{1}+k_{1}} \frac{\partial \gamma}{\partial r_{1}}\right]\right]=0,} \\
{\left[\frac{\partial^{2}}{\partial r_{1}{ }^{2}}+\frac{1}{r_{1}+k_{1}} \frac{\partial}{\partial r_{1}}\right] \phi+\frac{N_{t}}{N_{b}}\left[\frac{\partial^{2}}{\partial r_{1}^{2}}+\frac{1}{r_{1}+k_{1}} \frac{\partial}{\partial r_{1}}\right] \theta=0}
\end{gathered}
$$




$$
\frac{\partial^{2} \gamma}{\partial r_{1}^{2}}+\frac{1}{r_{1}+k_{1}} \frac{\partial \gamma}{\partial r_{1}}+L_{d}\left[\frac{\partial^{2} \theta}{\partial r_{1}^{2}}+\frac{1}{r_{1}+k_{1}} \frac{\partial \theta}{\partial r_{1}}\right]=0,
$$

by using the no-slip boundary conditions and compliant walls phenomenon [22,29]

$$
\left.\begin{array}{c}
U=c \text { at } r_{1}= \pm \eta= \pm\left(d_{1}+a \sin \left(\frac{2 \pi(X-c t)}{\lambda}\right)\right) \\
T=T_{0} \text { at } r_{1}=-\eta \text { and } T=T_{1} \text { at } r_{1}=\eta \\
C=C_{0} \text { at } r_{1}=-\eta \text { and } C=C_{1} \text { at } r_{1}=\eta \\
\varphi=\varphi_{0} \text { at } r_{1}=-\eta \text { and } \varphi=\varphi_{1} \text { at } r_{1}=\eta
\end{array}\right],
$$

After adopting wave frame phenomeno and creeping characteristics of the current ransport, we have the following conclusive form of the above-defined boundary relations in dimensionless format

$$
\begin{gathered}
u=0 \text { at } r_{1}= \pm \eta= \pm(1+\varepsilon \sin 2 \pi(x-t)), \\
\theta=0, \phi=0, \gamma=0 \text { at } r_{1}=-\eta, \\
\theta=1, \phi=1, \gamma=1 \text { at } r_{1}=\eta, \\
k\left[E_{1} \frac{\partial^{3}}{\partial x^{3}}+E_{2} \frac{\partial^{3}}{\partial x \partial t^{2}}+E_{3} \frac{\partial^{2}}{\partial t \partial x}\right] \eta=\frac{\partial p}{\partial x} \text { at } r_{1}= \pm \eta, \\
S_{r_{1} x}=-u_{r_{1}}+\frac{1}{r_{1}+k_{1}} u-2 \beta\left(u_{r_{1}}+\frac{1}{r_{1}+k_{1}} u\right)^{3} .
\end{gathered}
$$

where $E_{1}, E_{2}$, and $E_{3}$ are the representatives of the compliant wall properties [10].

\section{Solution of the Problem}

We utilize the method of series expansion to solve coupled differential equations which are given before. The deformation equations for $u, \theta, \gamma$, and $\phi$ are defined as [30]

$$
\begin{gathered}
(1-q) E\left[u-u_{0}\right]+q\left[\begin{array}{c}
-\frac{l}{r_{1}+k_{1}} \frac{\partial A}{\partial x}+\frac{1}{r_{1}+k_{1}} \frac{\partial}{\partial r_{1}}\left[\left(r_{1}+k_{1}\right)^{2} S_{r_{1} x}\right] \\
+N_{c} r_{1}+\theta-N_{r_{1}} \phi
\end{array}\right]=0, \\
(1-q) E\left[\theta-\theta_{0}\right]+q\left[\begin{array}{c}
\frac{\partial^{2} \theta}{\partial r_{1}^{2}}+\frac{1}{r_{1}+k_{1}} \frac{\partial \theta}{\partial r_{1}}+N_{b} \frac{\partial \varphi}{\partial r_{1}} \frac{\partial \theta}{\partial r_{1}}+N_{t}\left(\frac{\partial \theta}{\partial r_{1}}\right)^{2} \\
+N_{d}\left[\frac{\partial \gamma}{\partial r_{1}}+\frac{1}{r_{1}+k_{1}} \frac{\partial \gamma}{\partial r_{1}}\right]
\end{array}\right]=0, \\
(1-q) £\left[\varphi-\varphi_{0}\right]+q\left[\left[\frac{\partial^{2}}{\partial r_{1}^{2}}+\frac{1}{r_{1}+k_{1}} \frac{\partial}{\partial r_{1}}\right] \varphi+\frac{N_{t}}{N_{b}}\left[\frac{\partial^{2}}{\partial r_{1}^{2}}+\frac{1}{r_{1}+k_{1}} \frac{\partial}{\partial r_{1}}\right] \theta\right]=0, \\
(1-q) E\left[\gamma-\gamma_{0}\right]+q\left[\frac{\partial^{2} \gamma}{\partial r_{1}^{2}}+\frac{1}{r_{1}+k_{1}} \frac{\partial \gamma}{\partial r_{1}}+L_{d}\left[\frac{\partial^{2} \theta}{\partial r_{1}^{2}}+\frac{1}{r_{1}+k_{1}} \frac{\partial \theta}{\partial r_{1}}\right]\right]=0 .
\end{gathered}
$$

where $£$ is the linear operator which is chosen as $£=\frac{\partial^{2}}{\partial r_{1}^{2}}$. The initial guesses for $u, \theta, \phi$, and $\gamma$ are defined as

$$
\begin{gathered}
\bar{u}_{0}=\frac{1}{2 w_{1}}\left[-2\left(k_{1}+r_{1}\right) w \ln \left(k_{1}+r_{1}\right)+\left(k_{1}-w_{1}\right)\left(-r_{1}+w_{1}\right) \ln \left(k_{1}-w_{1}\right)+\right. \\
\left.\left(k_{1}+w_{1}\right)\left(r_{1}+w_{1}\right) \ln \left(k_{1}+w_{1}\right)\right], \\
\bar{\theta}_{0}=\frac{1}{2 w_{1}}\left[-2\left(k_{1}+r_{1}\right) w_{1} \ln \left(k_{1}+r_{1}\right)+\left(k_{1}-w_{1}\right)\left(r_{1}+w_{1}\right) \ln \left(k_{1}-w_{1}\right)+\right. \\
\left.\left(k_{1}+w_{1}\right)\left(r_{1}+w_{1}\right) \ln \left(k_{1}+w_{1}\right)\right], \\
\bar{\varphi}_{0}=\frac{1}{2 w_{1}}\left[-2\left(k_{1}+r_{1}\right) w_{1} \ln \left(k_{1}+r_{1}\right)+\left(k_{1}-w_{1}\right)\left(-r_{1}+w_{1}\right) \ln \left(k_{1}-w_{1}\right)+\right. \\
\left.\left(k_{1}+w_{1}\right)\left(r_{1}+w_{1}\right) \ln \left(k_{1}+w_{1}\right)\right],
\end{gathered}
$$




$$
\begin{gathered}
\bar{\gamma}_{0}=\frac{1}{2 w_{1}}\left[-2\left(k_{1}+r_{1}\right) w \ln \left(k_{1}+r_{1}\right)+\left(r_{1}-w_{1}\right)\left(r_{1}+w_{1}\right) \ln \left(k_{1}-w_{1}\right)+\right. \\
\left.\left(k_{1}+w_{1}\right)\left(r_{1}+w_{1}\right) \ln \left(k_{1}+w_{1}\right)\right] .
\end{gathered}
$$

Now we use the following perturbation series for $u, \theta, \gamma$, and $\phi$

$$
\left.\begin{array}{l}
u=u_{0}+q u_{1}+\ldots \\
\theta=\theta_{0}+q \theta_{1}+\ldots \\
\gamma=\gamma_{0}+q \gamma_{1}+\ldots \\
\varphi=\varphi_{0}+q \varphi_{1}+\ldots
\end{array}\right\} .
$$

After using the above series solutions in Equations (11) to (14) and comparing the coefficients of $q$, we get the same solutions for zeroth order terms and the first order systems found the following solutions

$$
\begin{aligned}
& u_{1}=C_{1}+r C_{2}-\frac{1}{4 \eta^{3}}\left(\frac { 1 } { 9 } r \eta ^ { 2 } \left(6 k\left(6+k+k \mathrm{~N}_{\mathrm{c}}-k \mathrm{~N}_{\mathrm{r} 1}+6 A\right) \eta+3(3+5 k)\left(1+\mathrm{N}_{\mathrm{c}}-\mathrm{N}_{\mathrm{r} 1}\right)\right.\right. \\
& \left.r \eta+\left(1+\mathrm{N}_{\mathrm{c}} \quad-\mathrm{N}_{\mathrm{r} 1}\right) r^{2}(3+5 \eta)\right)+\frac{1}{12(k+r)^{3}}\left(768(k+r)^{3} \beta \eta^{3} \log [k+r]^{3}\right. \\
& -3 \beta(k-\eta)^{3}(k+\eta)\left(17 k^{2}+40 k r+24 r^{2}-6 k \eta-8 r \eta+\eta^{2}\right) \log [k-\eta]^{3} \\
& +288(k+r)^{2} \beta \eta^{2} \log [k+r]^{2}(12(k+r) \eta+(k-\eta)(3 k+4 r-\eta) \log [k-\eta] \\
& -(k+\eta)(3 k+4 r+\eta) \log [k+\eta])+\beta(k-\eta)^{2}(k+\eta) \log [k-\eta]^{2}(-8(k+r)(31 k+36 r-5 \eta) \eta \\
& \left.+3\left(3 k\left(17 k^{2}+40 k r+24 r^{2}\right) \eta+(5 k+8 r) \eta^{2}-3 \eta^{3}\right) \log [k+\eta]\right) \\
& +(k+\eta) \log [k+\eta]\left(4 ( k + r ) ^ { 2 } \eta ^ { 2 } \left(r^{3}\left(6+r+\mathrm{N}_{\mathrm{c}} r-\mathrm{N}_{\mathrm{r} 1} r\right)+3\left(1+\left(1+\mathrm{N}_{\mathrm{c}}-\mathrm{N}_{\mathrm{r} 1}\right) r^{3}-30 \beta\right) \eta\right.\right. \\
& \left.+k\left(-3+90 \beta+r^{2}\left(6+r+\mathrm{N}_{\mathrm{c}} r-\mathrm{N}_{\mathrm{r} 1} r+3\left(1+\mathrm{N}_{\mathrm{c}}-\mathrm{N}_{\mathrm{r} 1}\right) \eta\right)\right)\right) \\
& +\beta(k-\eta)(k+\eta) \log [k+\eta](-8(k+r) \eta(31 k+36 r+5 \eta) \\
& \left.\left.+3(k+\eta)\left(17 k^{2}+40 k r+24 r^{2}+6 k \eta+8 r \eta+\eta^{2}\right) \log [k+\eta]\right)\right) \\
& -(k-\eta) \log [k-\eta]\left(4 ( k + r ) ^ { 2 } \eta ^ { 2 } \left(r^{3}\left(6+r+\mathrm{N}_{\mathrm{c}} r-\mathrm{N}_{\mathrm{r} 1} r\right)-3\left(1+\left(1+\mathrm{N}_{\mathrm{c}}-\mathrm{N}_{\mathrm{r} 1}\right) r^{3}-30 \beta\right) \eta\right.\right. \\
& \left.+k\left(-3+90 \beta+r^{2}\left(6+r+\mathrm{N}_{\mathrm{c}} r-\mathrm{N}_{\mathrm{r} 1} r-3\left(1+\mathrm{N}_{\mathrm{c}}-\mathrm{N}_{\mathrm{r} 1}\right) \eta\right)\right)\right) \\
& +\beta(k+\eta) \log [k+\eta]\left(-16(k+r) \eta\left(31 k^{2} k r+5 \eta^{2}\right)+3(k+\eta)\left(3 k\left(17 k^{2}+40 k r+24 r^{2}\right)\right.\right. \\
& \left.\left.\left.-\left(11 k^{2}+32 k r+24 r^{2}\right) \eta+(5 k+8 r) \eta^{2}+3 \eta^{3}\right) \log [k+\eta]\right)\right) \\
& -8(k+r) \eta \log [k+r]\left(( k + r ) ^ { 2 } \left(6+(k+r)\left(k^{2}\left(1+\mathrm{N}_{\mathrm{c}}-\mathrm{N}_{\mathrm{r} 1}\right)\right.\right.\right. \\
& \left.\left.+r\left(6+r+\mathrm{N}_{\mathrm{c}} r-\mathrm{N}_{\mathrm{r} 1} r\right)+2 k\left(3+3 A+r+\mathrm{N}_{\mathrm{c}} r-\mathrm{N}_{\mathrm{r} 1} r\right)\right)-936 \beta\right) \eta^{2} \\
& +6 \beta\left(-(k-\eta)^{2}\left(7 k^{2}+18 k+12 r^{2}-4 k \eta-6 r \eta+\eta^{2}\right) \log [k-\eta]^{2}\right. \\
& +2(k-\eta) \log [k-\eta](-6(k+r)(5 k+6 r-\eta) \eta \\
& \left.+(k+\eta)\left(7 k^{2}+18 k r+12 r^{2}-\eta^{2}\right) \log [k+\eta]\right) \\
& +(k+\eta) \log [k+\eta](12(k+r) \eta(5 k+6 r+\eta) \\
& \left.\left.\left.\left.\left.-(k+\eta)\left(7 k^{2}+18 k r+12 r^{2}+4 k \eta+6 r \eta+\eta^{2}\right) \log [k+\eta]\right)\right)\right)\right)\right), \\
& \theta_{1}=C_{3}+r C_{4}-\frac{1}{4 \eta^{2}}\left(2(k+r)\left(-1-\mathrm{Nd}+\left(\mathrm{N}_{\mathrm{b}}+\mathrm{N}_{\mathrm{t}}\right)(k+r)\right) \eta^{2} \log [k+r]^{2}\right. \\
& +2(k+r) \eta+\log [k+r]\left(1+\mathrm{N}_{\mathrm{d}}-\left(\mathrm{N}_{\mathrm{b}}+\mathrm{N}_{\mathrm{t}}\right)(k+r)-2 \eta\right. \\
& -\left(2 \mathrm{~N}_{\mathrm{d}}+\left(\mathrm{N}_{\mathrm{b}}+\mathrm{N}_{\mathrm{t}}\right)(k+r)\right) \eta+\left(-1-\mathrm{N}_{\mathrm{d}}+\left(\mathrm{N}_{\mathrm{b}}+\mathrm{N}_{\mathrm{t}}\right)(k\right. \\
& +r))((k-\eta) \log [k-\eta]-(k+\eta) \log [k+\eta]))+\frac{1}{2} r\left(\left(\mathrm{~N}_{\mathrm{b}}\right.\right. \\
& \left.+\mathrm{N}_{\mathrm{t}}\right) r+2\left(-2\left(1+\mathrm{N}_{\mathrm{d}}\right)+\left(\mathrm{N}_{\mathrm{b}}+\mathrm{N}_{\mathrm{t}}\right)(2 k+r)\right) \eta+2\left(4+4 \mathrm{~N}_{\mathrm{d}}\right. \\
& \left.+2 k\left(\mathrm{~N}_{\mathrm{b}}+\mathrm{N}_{\mathrm{t}}\right)+3\left(\mathrm{~N}_{\mathrm{b}}+\mathrm{N}_{\mathrm{t}}\right) r\right) \eta^{2}+((k-\eta) \log [k-\eta]-(k \\
& +\eta) \log [k+\eta])\left(-2\left(\mathrm{~N}_{\mathrm{b}}+\mathrm{N}_{\mathrm{t}}\right) r-2\left(-2\left(1+\mathrm{N}_{\mathrm{d}}\right)+\left(\mathrm{N}_{\mathrm{b}}\right.\right.\right. \\
& \left.\left.+\mathrm{N}_{\mathrm{t}}\right)(2 k+r)\right) \eta+\left(\mathrm{N}_{\mathrm{b}}+\mathrm{N}_{\mathrm{t}}\right) r((k-\eta) \log [k-\eta]-(k \\
& +\eta) \log [k+\eta])))) \text {, } \\
& \phi_{1}=C_{5}+r C_{6}+\frac{1}{2 N_{b} \eta}\left(( \mathrm { N } _ { \mathrm { b } } + \mathrm { N } _ { \mathrm { t } } ) ( k + r ) \left(1-2 \eta+\eta \log [k+r]^{2}\right.\right. \\
& +(-k+\eta) \log [k-\eta]+(k+\eta) \log [k+\eta]-\log [k+r](1-2 \eta \\
& +(-k+\eta) \log [k-\eta]+(k+\eta) \log [k+\eta]))),
\end{aligned}
$$




$$
\begin{aligned}
\gamma_{1}=C_{7}+r C_{8} & +\frac{1}{2 \eta}\left(( 1 + \mathrm { L } _ { \mathrm { d } } ) ( k + r ) \left(1-2 \eta+\eta \log [k+r]^{2}\right.\right. \\
& +(-k+\eta) \log [k-\eta]+(k+\eta) \log [k+\eta]-\log [k+r](1-2 \eta \\
& +(-k+\eta) \log [k-\eta]+(k+\eta) \log [k+\eta]))),
\end{aligned}
$$

where the constants $C_{i}, i=1,2,3, \ldots 8$ can be found by using boundary conditions are described in the Appendix A and the quantity $A(x, t)$ contains the subsequent expression

$$
A(x, t)=-2 \varepsilon \pi^{3} k\left\{\frac{E_{3}}{2 \pi} \sin (x-t) 2 \pi-\left(E_{1}+E_{2}\right) \cos (x-t) 2 \pi\right\} .
$$

Therefore, the final solutions can be composed by injecting above evaluated expressions of $u_{0}, \theta_{0}, \phi_{0}, \gamma_{0}$ and $u_{1}, \theta_{1}, \phi_{1}, \gamma_{1}$ into Equation (24).

The expression for the heat transfer coefficient is described as

$$
z=\eta_{x} \theta_{r}(\eta)
$$

Hence, it is calculated as

$$
\begin{aligned}
z= & -\frac{1}{2+2 \epsilon \operatorname{Sin}[2 \pi(-t+x)]} \pi \epsilon \operatorname{Cos}[2 \pi(-t+x)]\left(5(\mathrm{Nb}+\mathrm{Nt})-4 C_{4}+(-1+k)^{2}(\mathrm{Nb}\right. \\
& +\mathrm{Nt}) \log [-1+k+\epsilon \operatorname{Sin}[2 \pi(t-x)]]^{2} \\
& +2(-1+k) \log [-1+k+\epsilon \operatorname{Sin}[2 \pi(t-x)]](-\mathrm{Nb}-\mathrm{Nt} \\
& +(-1+\mathrm{Nb}+k \mathrm{Nb}-\mathrm{Nd}+\mathrm{Nt}+k \mathrm{Nt}) \log [1+k+\epsilon \operatorname{Sin}[2 \pi(-t+x)]])+\log [1+k \\
& +\epsilon \operatorname{Sin}[2 \pi(-t+x)]]\left(-2(3+\mathrm{Nb}+k \mathrm{Nb}+3 \mathrm{Nd}+\mathrm{Nt}+k \mathrm{Nt})+\left(\mathrm{Nb}+\mathrm{Nt}-3 k^{2}(\mathrm{Nb}\right.\right. \\
& +\mathrm{Nt})-2 k(-1+\mathrm{Nb}-\mathrm{Nd}+\mathrm{Nt}) \log [1+k+\epsilon \operatorname{Sin}[2 \pi(-t+x)]])+\epsilon \operatorname{Sin}[2 \pi(-t \\
& +x)]\left(2 \left(4(\mathrm{Nb}+\mathrm{Nt})-2 \mathrm{C}[2]-(-1+k)(\mathrm{Nb}+\mathrm{Nt}) \log [-1+k+\epsilon \operatorname{Sin}[2 \pi(t-x)]]^{2}\right.\right. \\
& -(4+\mathrm{Nb}+4 \mathrm{Nd}+\mathrm{Nt}) \log [1+k+\epsilon \operatorname{Sin}[2 \pi(-t+x)]]-(-1+k)(\mathrm{Nb}+\mathrm{Nt}) \log [1+k \\
& +\epsilon \operatorname{Sin}[2 \pi(-t+x)]]^{2}+\log [-1+k+\epsilon \operatorname{Sin}[2 \pi(t-x)]](\mathrm{Nb}+\mathrm{Nt}+(1-2 \mathrm{Nb}+\mathrm{Nd} \\
& -2 \mathrm{Nt}) \log [1+k+\epsilon \operatorname{Sin}[2 \pi(-t+x)]]))+(\mathrm{Nb}+\mathrm{Nt}) \epsilon(4+(\log [-1+k+\epsilon \operatorname{Sin}[2 \pi(t \\
& \left.\left.\left.-x)]]-\log [1+k+\epsilon \operatorname{Sin}[2 \pi(-t+x)]])^{2}\right) \operatorname{Sin}[2 \pi(-t+x)]\right)\right) .
\end{aligned}
$$

\section{Graphical Results and Discussion}

The above analysis composes the effects of double diffusion on pumping flow of non-Newtonian (third order) fluid travelling through a curved channel and also described the wall properties. The formulation is carried out by introducing non-dimensional parameters and imposing the features of the lubrication approach. After achieving system of four nonlinear coupled differential equations, exact analytical solutions have been found by an appropriate analytical highly converging technique (HPM). In this segment of the study, we have included graphical treatment of various obtained quantities like comparison graph, velocity, temperature, solutal concentration, and nanoparticle phenomenon. Figure $1 \mathrm{~b}$ is included just to validate the present results by comparing analytical solution with exact solution [25]. This graph contains the data of velocity obtained in the current study by neglecting the effects of double diffusion convection $\left(N_{c}=N_{r 1}=0\right)$ and the data of [25]. One can find the reading that the current analytical solutions are very much in agreement with the exact solutions found by Hayat et al. [25]. In Figure 2, the velocity is displayed under the variation of the regular buoyancy ratio $N_{c}$. We conclude from this figure that the velocity of fluid is increasing with increasing quantity of $N_{c}$ and become highest in the middle part of the channel. This result stresses that $N_{c}$ being the ration of concentration variance to temperature gradient, when gets increased meant that concentration change is higher than the temperature difference which is actually causing the fluid to travel with greater intensity. From Figure 3, it is very clear that the velocity is showing totally opposite behavior against the buoyancy parameter $N_{r 1}$ as compared to $N_{c}$ which is also prominent physically that when we increase the density of particles the fluid travels slowly. Figure 4 is portrayed to find the influence of complaint wall parameters $E_{1}, E_{2}, E_{3}$ and it can be concluded here that the velocity of the nanofluid is minimized with the complaint wall parameters. In Figure 5, the temperature profile 
$\theta$ is portrayed to measure the influence of the regular buoyancy parameter $N_{b}$. According to this graph, it is noticed that the temperature is increasing with the increasing value of $N_{b}$ and the highest temperature is observed at $r=0.2$, which is near the centerline of channel. Figure 6 is showing the effect of a modified Dufour parameter $N_{d}$ on temperature profile $\theta$. This graph is emphasized that $N_{d}$ is lowering the temperature throughout the geometry which represents the cooling effects due to change in nanoparticles concentration. The temperature profile $\theta$ for various values of thermophoresis parameter $N_{t}$ is plotted in Figure 7. According to this figure, we can analyze that as we increase the magnitude of $N_{t}$, the temperature $\theta$ is also increased and gets higher magnitude in the central region of the channel. Figures 8 and 9 highlights the variation of nanoparticle concentration $\phi$ when there is an increase the values of Brownian motion parameter $N_{b}$ and thermophoresis parameter $N_{t}$. It can be supposed from these figures that nanoparticle concentration is increasing with $N_{b}$ but decreasing with $N_{t}$. It is also observed that nanoparticles are less in numbers in the central part and minimum quantity is at the position $r=h$. Figures 10 and 11 are drawn to manage the behavior of curvature parameter $k$ and Defour-Solutal Lewis number $L_{d}$ on solutal concentration. Figure 10 depicts that $\gamma$ is increasing with the increasing values of $k$. It means that as we use the curved channel with large curvature, the solutal concentration will get increased. On the other hand, Figure 11 emphasizes that $\gamma$ is decreasing with $L_{d}$ and quite opposite behaviour is observed in this figure as we have seen from Figure 10. Figures 12-14 are captured to visualize the effects the $N_{b}, N_{d}$, and $N_{t}$ respectively on the heat transfer coefficient $z$. It is found from these figures that heat transfer is decreasing with $N_{b}$ and $N_{t}$ on the left and right sides but increasing in the centre. It is depicted here that $N_{d}$ reflects the opposite behaviour on heat transfer. It is also noted from Figures 12-14 that amount of heat transfer is maximum at the center of the channel.

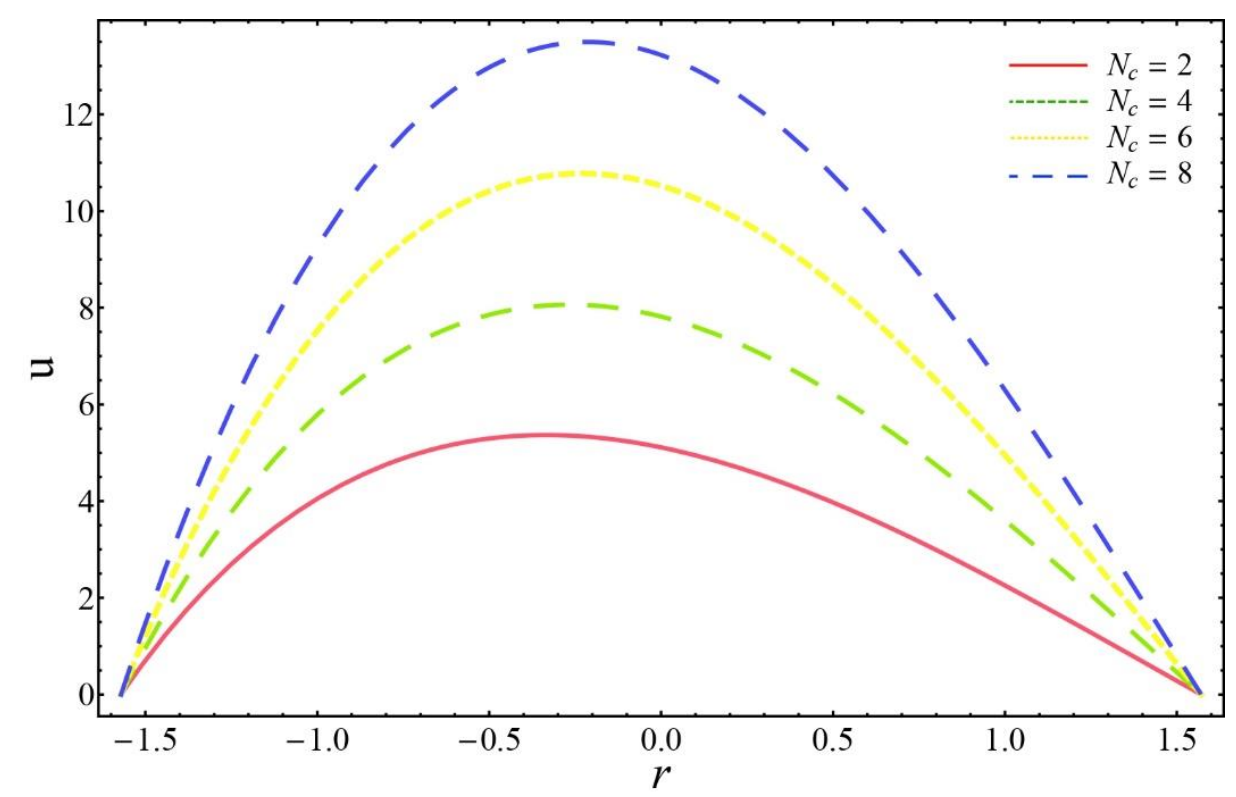

Figure 2. Alteration of $N_{c}$ on $\mathrm{u}$ when $x=0.2 ; t=0 ; Q=10 ; \beta=0.1 ; \epsilon=0.6 ; N_{r 1}=2 ; k=2$; $E_{1}=0.1 ; E_{2}=0.1 ; E_{3}=0.9$. 


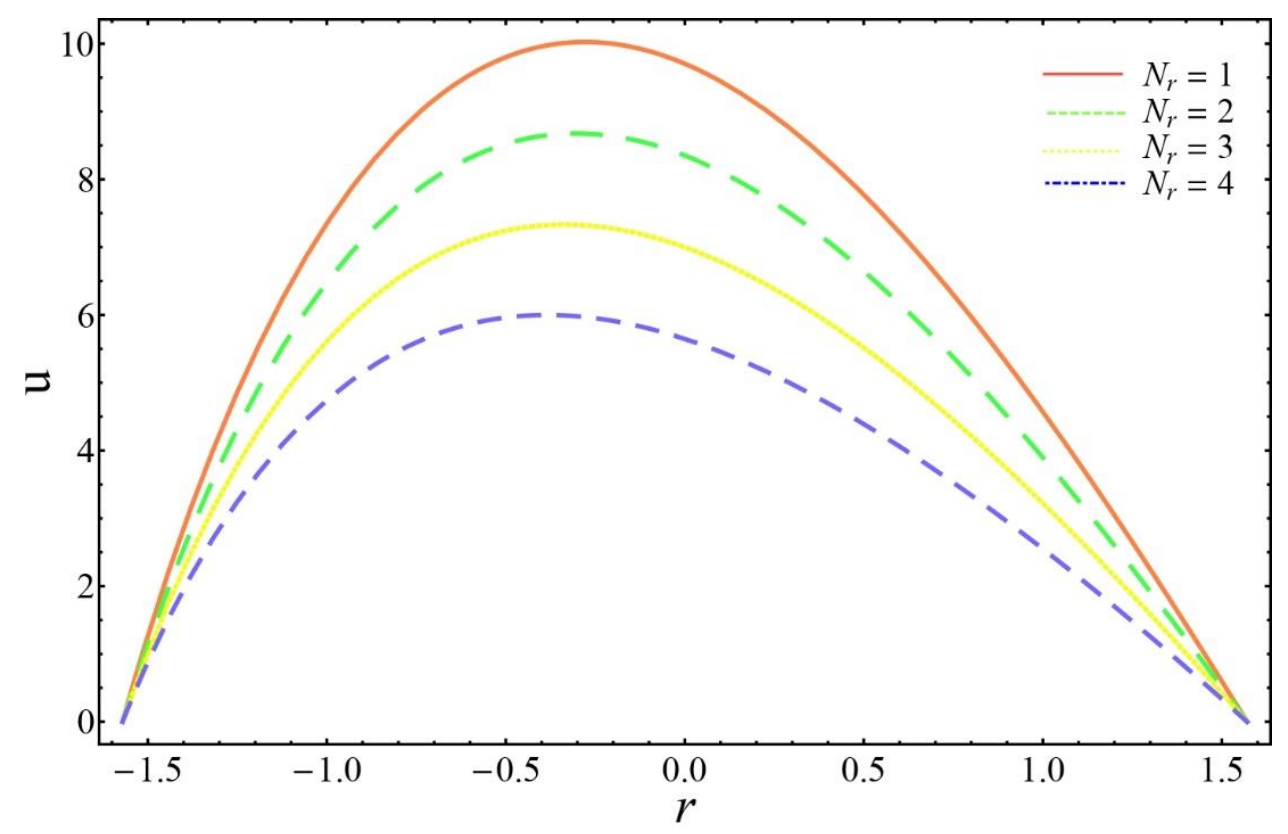

Figure 3. Alteration of $N_{r 1}$ on $\mathrm{u}$ when $x=0.2 ; t=0 ; Q=10 ; \beta=0.1 ; \epsilon=0.6 ; N_{c}=2 ; k=2$; $E_{1}=0.1 ; E_{2}=0.1 ; E_{3}=0.9$.

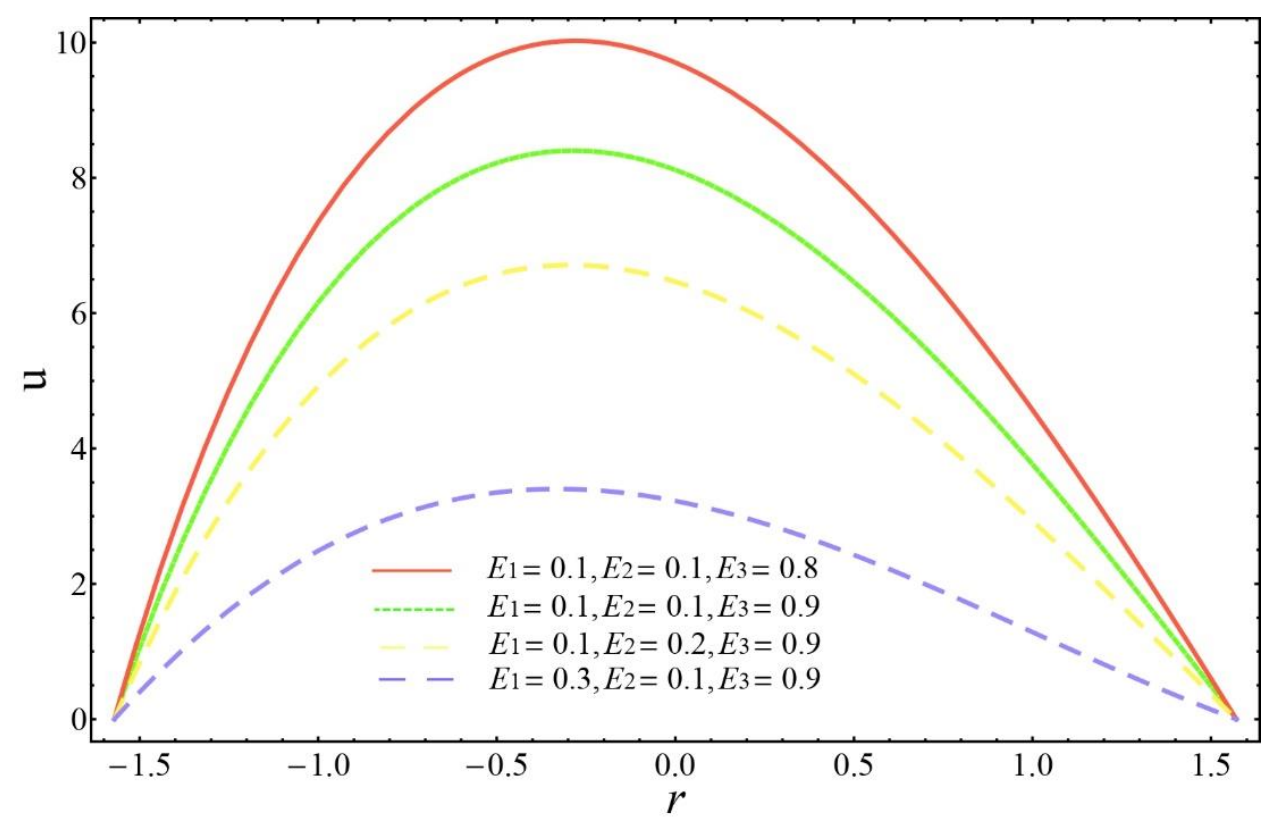

Figure 4. Variation of complaint wall parameters on $\mathrm{u}$ when $\epsilon=0.6 ; \beta=0.01 ; k=2 ; x=0.2$; $t=0 ; N_{c}=2 ; N_{r 1}=1 ; Q=10$. 


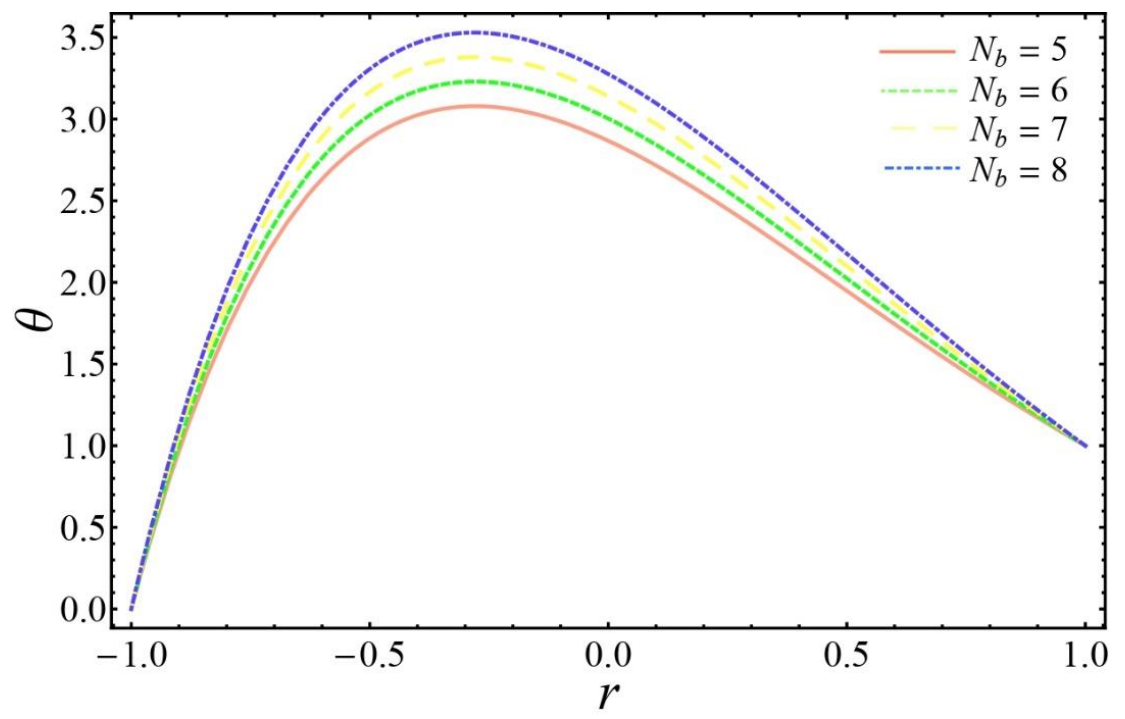

Figure 5. Alteration of $N_{b}$ on $\theta$ when $x=0.5 ; t=0 ; Q=10 ; \beta=0.2 ; \epsilon=0.6 ; N_{t}=5 ; N_{d}=2 ; k=2$.

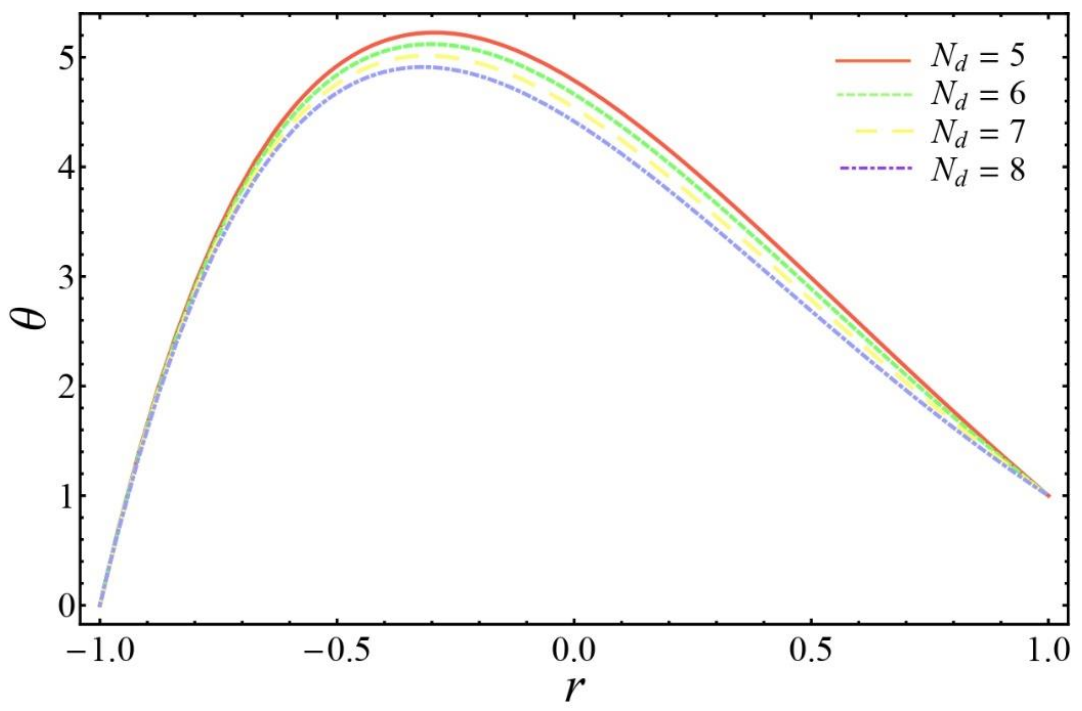

Figure 6. Alteration of $N_{d}$ on $\theta$ when $x=0.5 ; t=0 ; Q=10 ; \beta=0.2 ; \epsilon=0.6 ; N_{t}=5 ; N_{b}=2 ; k=2$.

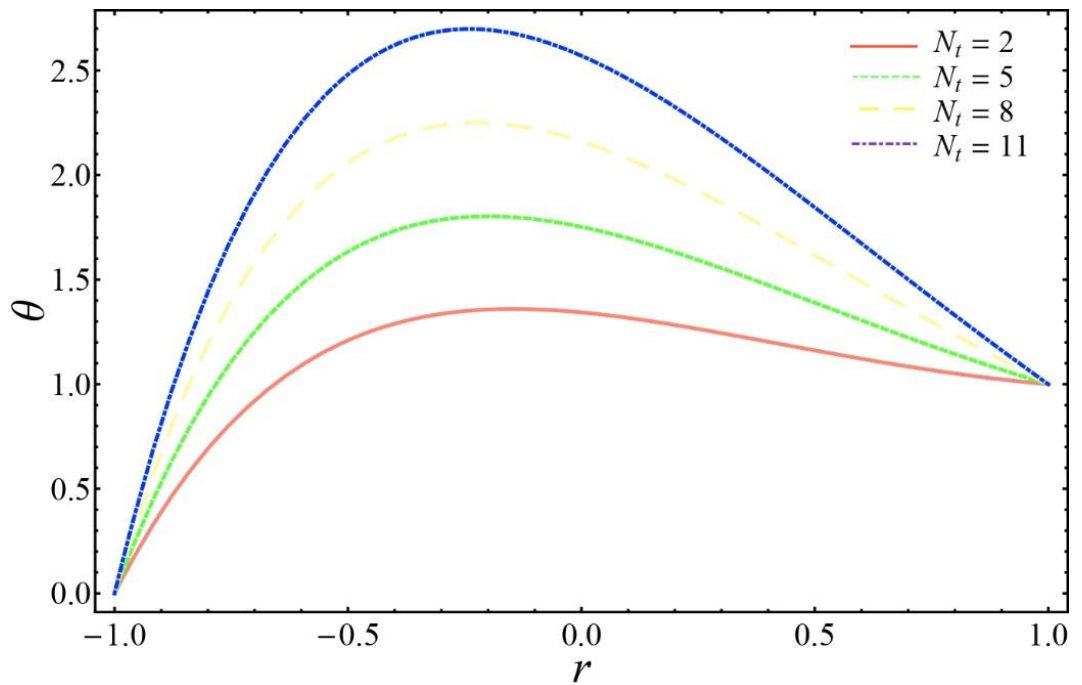

Figure 7. Alteration of $N_{t}$ on $\theta$ when $x=0.5 ; t=0 ; Q=10 ; \beta=0.2 ; \epsilon=0.2 ; N_{b}=5 ; N_{d}=2 ; k=2$. 


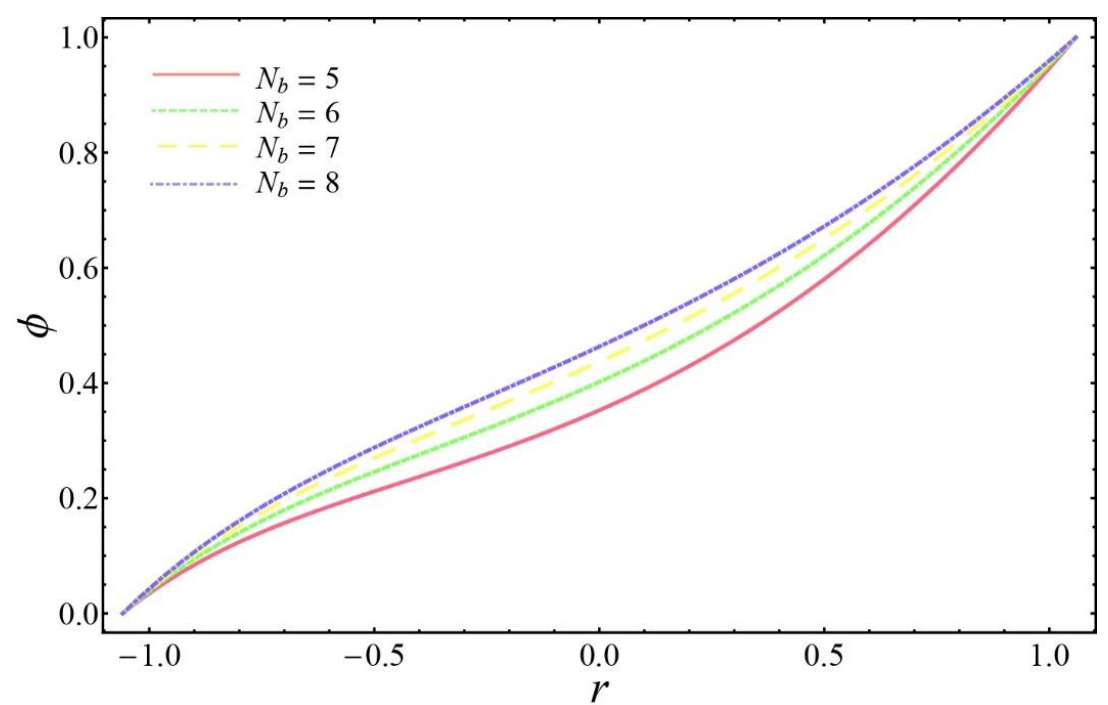

Figure 8. Alteration of $N_{b}$ on $\phi$ when $x=0.1 ; t=0 ; Q=10 ; \beta=0.2 ; \epsilon=0.1 ; N_{t}=10 ; N_{d}=2 ; k=2$.

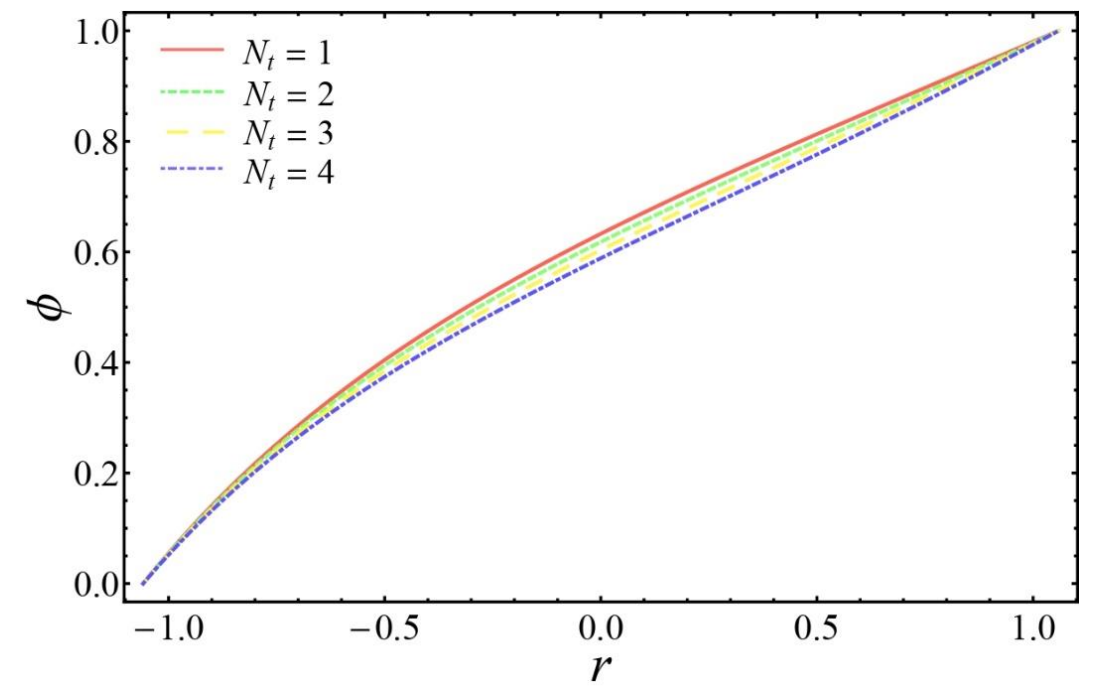

Figure 9. Alteration of $N_{t}$ on $\phi$ when $x=0.1 ; t=0 ; Q=10 ; \beta=0.2 ; \epsilon=0.1 ; N_{b}=10 ; N_{d}=2 ; k=2$.

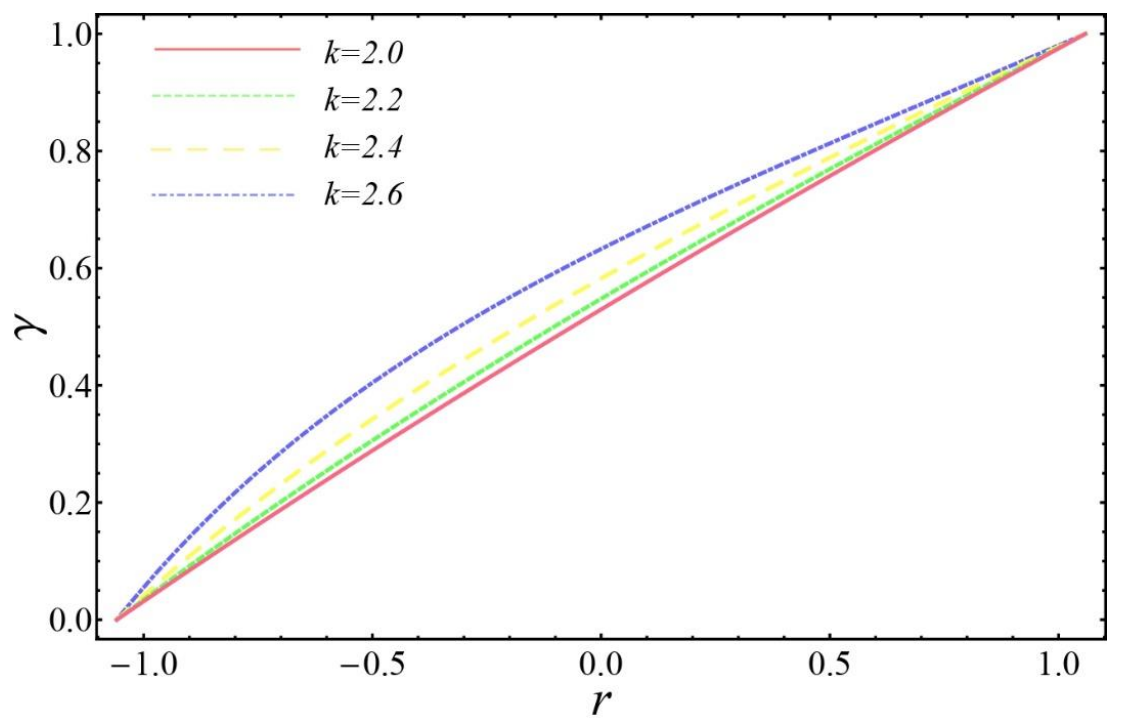

Figure 10. Alteration of $k$ on $\gamma$ when $x=0.1 ; t=0 ; Q=10 ; \beta=0.2 ; \epsilon=0.1 ; N_{b}=2 ; N_{d}=1 ; L_{d}=0.1$. 


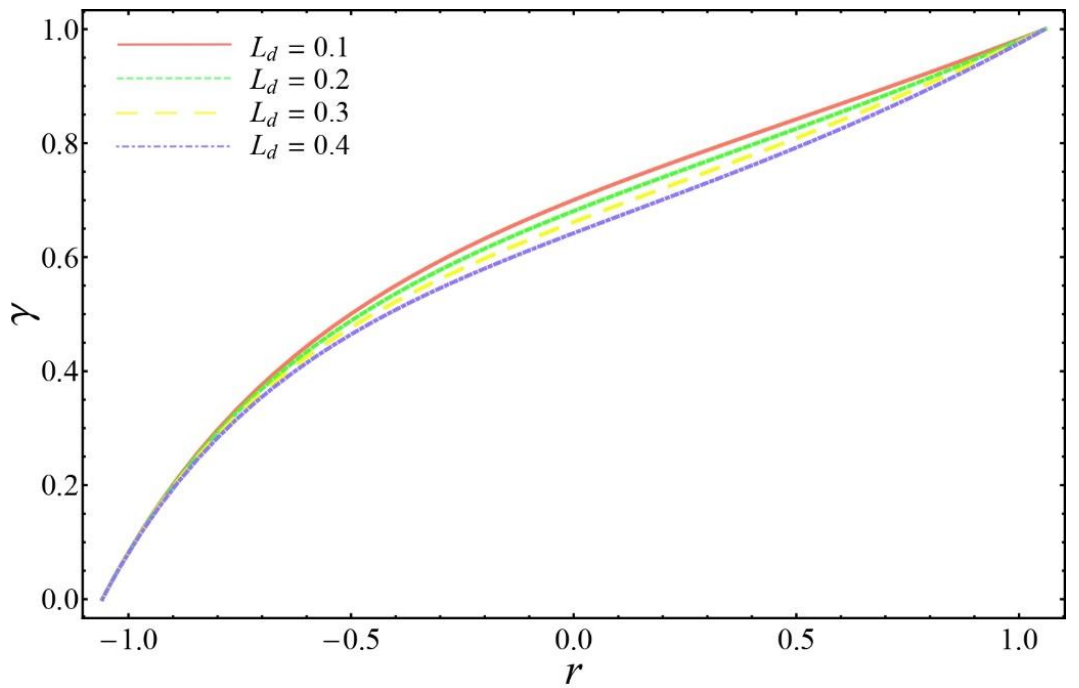

Figure 11. Alteration of $L_{d}$ on $\gamma$ when $x=0.1 ; t=0 ; Q=10 ; \beta=0.2 ; \epsilon=0.1 ; N_{b}=2 ; N_{d}=1 ; k=1.5$.

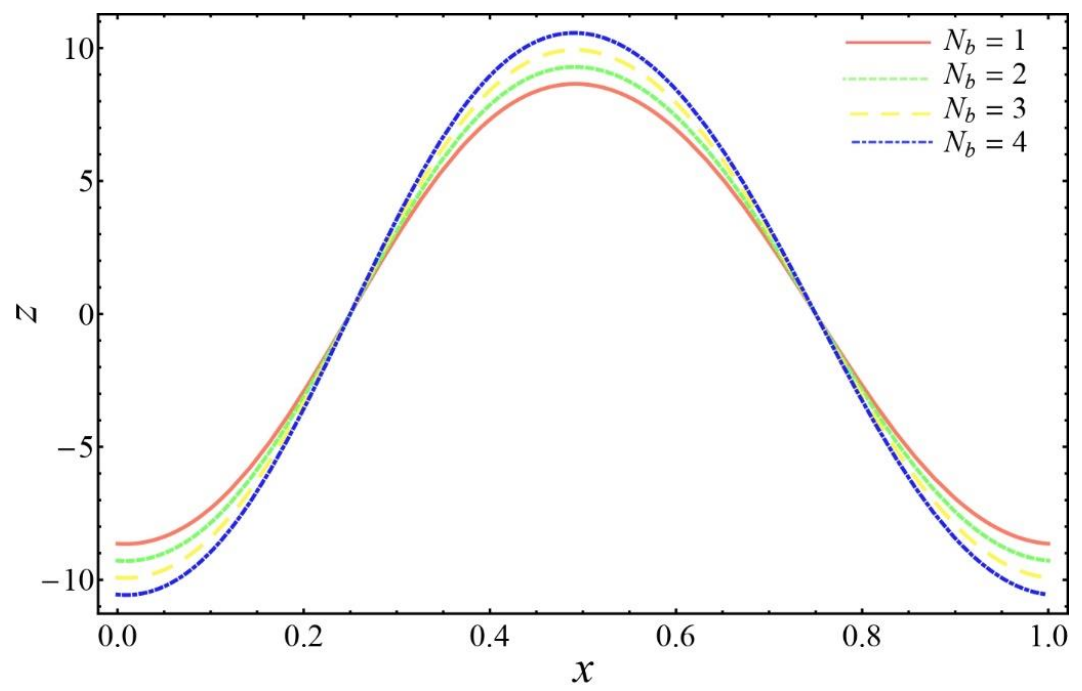

Figure 12. Alteration of $N_{b}$ on $z$ when $t=0 ; Q=10 ; \beta=0.2 ; \epsilon=0.2 ; N_{t}=15 ; N_{d}=2 ; k=2$.

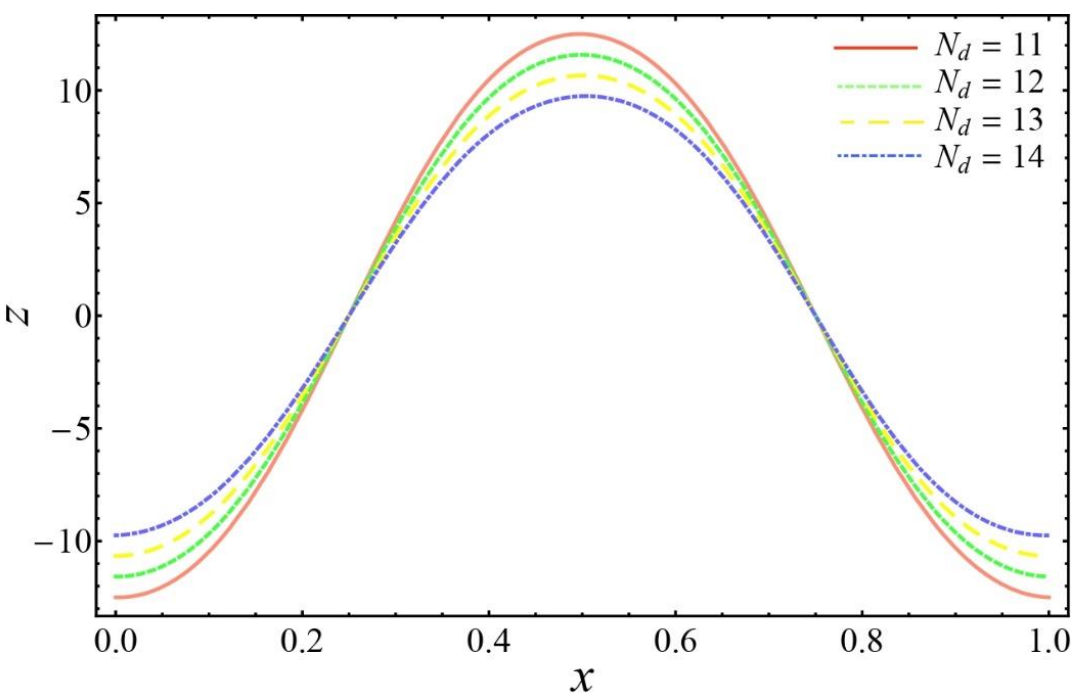

Figure 13. Alteration of $N_{d}$ on $z$ when $t=0 ; Q=10 ; \beta=0.2 ; \epsilon=0.2 ; N_{t}=15 ; N_{b}=20 ; k=2$. 


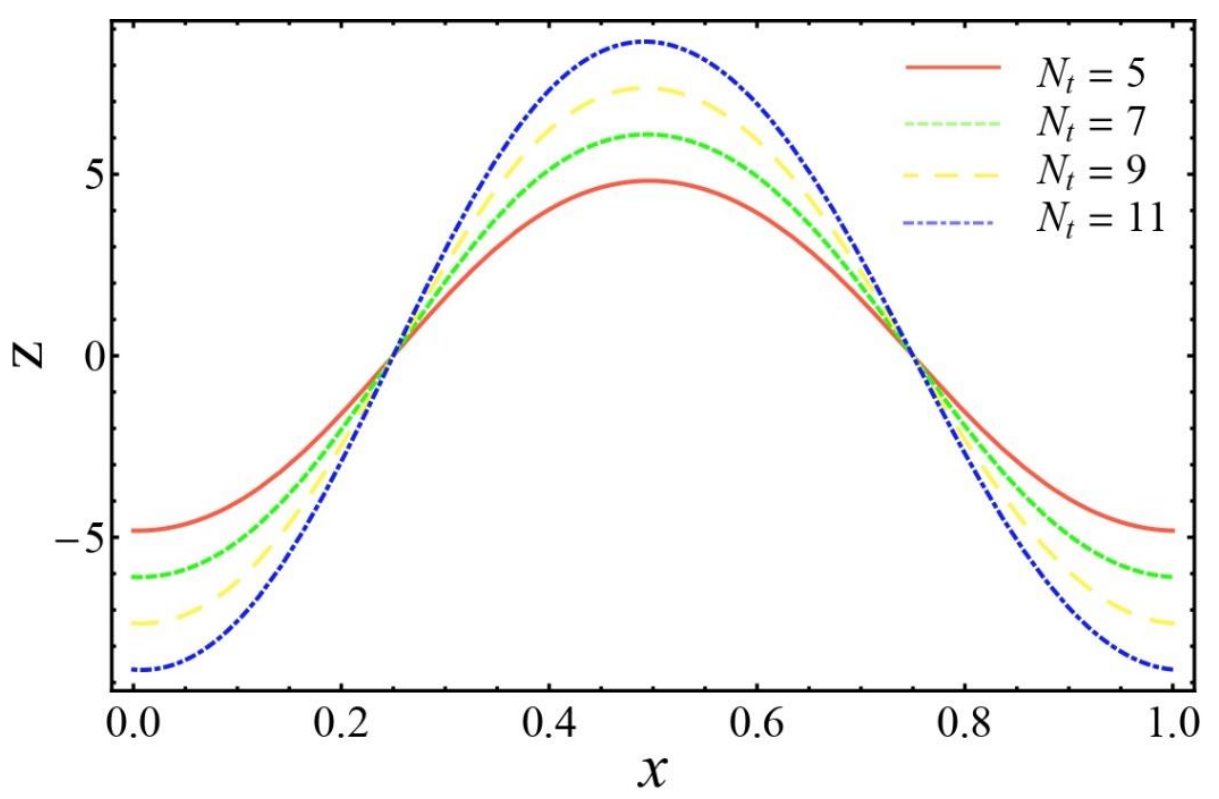

Figure 14. Alteration of $N_{t}$ on $z$ when $t=0 ; Q=10 ; \beta=0.2 ; \epsilon=0.2 ; N_{b}=5 ; N_{d}=2 ; k=2$.

\section{Conclusions}

In the third chapter, we have presented the effect of double diffusion on the peristaltic flow of nanofluid through a curved channel. The governing equations for velocity, temperature, nanoparticles, and solutal concentration have been modified and illustrated under the suppositions of low Reynolds number and low wavelength. The solutions have been carried out by HPM. In the last section, graphical results have been sketched through figures. The major points of the study are given below:

- The velocity profile increases with an increasing regular buoyancy ratio, but buoyancy parameter and compliant walls give opposite effects on velocity.

- The temperature increases with the Brownian motion parameter and thermophoresis parameter, but decreases with the buoyancy parameter. It is also noticed that the maximum temperature is observed in the center of the channel.

- The nanoparticles increase with the variation of regular buoyancy parameter, but decrease with increasing thermophoresis parameter. Moreover, it is concluded that in the center, there are fewer numbers of nanoparticles as compared to the left side boundary.

- It is observed that as an increase in the curvature of the channel, solutal concentration is increased, but reveals opposite behavior with Defour-Solutal Lewis number.

- It is found that heat is transferred in large amounts while increasing a modified Dufour parameter, but the less heat transfer is observed in case of Brownian motion parameter and thermophoresis parameter.

- It is disclosed that current analytical study is in line with the study [25] having exact solutions by skipping the terms of double diffusion.

Author Contributions: Conceptualization, H.A.; methodology, N.S.; software, A.R. (Abdul Razaq).; validation, A.Z. \& M.M.B.; formal analysis and investigation, A.R. (Arshad Riaz); writing-original draft preparation, N.S.; writing-review and editing, H.A.; funding acquisition, H.A. All authors have read and agreed to the published version of the manuscript.

Funding: The authors extend their appreciation to the Deanship of Scientific Research at King Saud University for funding this work through research group No (RG- 1440-114).

Conflicts of Interest: The authors declare no conflict of interest. 


\section{Appendix A}

$$
\begin{aligned}
& C_{1}=-\frac{1}{48 \eta^{3}} \quad\left(-4(3+5 k)\left(1+\mathrm{N}_{\mathrm{c}}-\mathrm{N}_{\mathrm{r}}\right) \eta^{5}+3 \beta\left(17 k^{3}-96 k^{2} \eta+51 k \eta^{2}-32 \eta^{3}\right) \log [k-\eta]^{3}\right. \\
& +\beta \log [k-\eta]^{2}\left(8 \eta\left(31 k^{2}-216 k \eta+31 \eta^{2}\right)-9\left(17 k^{3}-32 k^{2} \eta-77 k \eta^{2}+32 \eta^{3}\right) \log [k+\eta]\right) \\
& +\log [k-\eta]\left(4 \eta ^ { 2 } \left(3 k(-1+30 \beta)+\left(6+k^{2}\left(6+k+k \mathrm{~N}_{\mathrm{c}}-k \mathrm{~N}_{\mathrm{r}}+6 A\right)-936 \beta\right) \eta\right.\right. \\
& \left.-3 k\left(2+k+k \mathrm{~N}_{\mathrm{c}}-k \mathrm{~N}_{\mathrm{r}}+2 A\right) \eta^{2}+2\left(1+\mathrm{N}_{\mathrm{c}}-\mathrm{N}_{\mathrm{r}}\right) \eta^{4}\right)+\beta \log [k+\eta]\left(-496 k^{2} \eta\right. \\
& \left.\left.+2960 \eta^{3}+9\left(17 k^{3}+32 k^{2} \eta-77 k \eta^{2}-32 \eta^{3}\right) \log [k+\eta]\right)\right)+\log [k+\eta]\left(4 \eta^{2}(k(3\right. \\
& -90 \beta)+\left(6+k^{2}\left(6+k+k \mathrm{~N}_{\mathrm{c}}-k \mathrm{~N}_{\mathrm{r}}+6 A\right)-936 \beta\right) \eta+3 k\left(2+k+k \mathrm{~N}_{\mathrm{c}}-k \mathrm{~N}_{\mathrm{r}}\right. \\
& \left.+2 A) \eta^{2}-2\left(1+\mathrm{N}_{\mathrm{c}}-\mathrm{N}_{\mathrm{r}}\right) \eta^{4}\right)+\beta \log [k+\eta]\left(8 \eta\left(31 k^{2}+216 k \eta+31 \eta^{2}\right)-3\left(17 k^{3}\right.\right. \\
& \left.\left.\left.+96 k^{2} \eta+51 k \eta^{2}+32 \eta^{3}\right) \log [k+\eta]\right)\right) \text { ), } \\
& C_{2}=\frac{1}{144 \eta^{3}} \quad\left(4 \eta^{3}\left(6 k^{2}\left(1+\mathrm{N}_{\mathrm{c}}-\mathrm{N}_{\mathrm{r}}\right)+36 k(1+A)+\left(1+\mathrm{N}_{\mathrm{c}}-\mathrm{N}_{\mathrm{r}}\right) \eta(3+5 \eta)\right)+3\left(-45 \beta\left(3 k^{2}+\eta^{2}\right) \log [k-\eta]^{3}\right.\right. \\
& +\beta \log [k-\eta]^{2}\left(-1232 k \eta+135\left(3 k^{2}+\eta^{2}\right) \log [k+\eta]\right)+\log [k-\eta]\left(4 \eta^{2}(3\right. \\
& \left.-846 \beta+(k-\eta)\left(k\left(6+k+k \mathrm{~N}_{\mathrm{c}}-k \mathrm{~N}_{\mathrm{r}}+6 A\right)-2\left(3+k\left(1+\mathrm{N}_{\mathrm{c}}-\mathrm{N}_{\mathrm{r}}\right)\right) \eta\right)\right)+\beta \log [k+\eta](2464 k \eta \\
& \left.\left.-135\left(3 k^{2}+\eta^{2}\right) \log [k+\eta]\right)\right)+\log [k+\eta]\left(4 \eta ^ { 2 } \left(-3+846 \beta-(k+\eta)\left(6 \eta+k\left(6+k+k \mathrm{~N}_{\mathrm{c}}-k \mathrm{~N}_{\mathrm{r}}\right.\right.\right.\right. \\
& \left.\left.\left.\left.\left.+6 A+2\left(1+\mathrm{N}_{\mathrm{c}}-\mathrm{N}_{\mathrm{r}}\right) \eta\right)\right)\right)+\beta \log [k+\eta]\left(-1232 k \eta+45 \times\left(3 k^{2}+\eta^{2}\right) \log [k+\eta]\right)\right)\right), \\
& C_{3}=\frac{1}{8 \eta} \quad\left(\left(\mathrm{N}_{\mathrm{b}}+\mathrm{N}_{\mathrm{t}}\right) \eta\left(1+2 \eta+6 \eta^{2}\right)+(k-\eta)\left(2 k^{2}\left(\mathrm{~N}_{\mathrm{b}}+\mathrm{N}_{\mathrm{t}}\right)-\left(\mathrm{N}_{\mathrm{b}}+\mathrm{N}_{\mathrm{t}}\right) \eta^{2}-k\left(2+2 \mathrm{~N}_{\mathrm{d}}\right.\right.\right. \\
& \left.\left.+\left(\mathrm{N}_{\mathrm{b}}+\mathrm{N}_{\mathrm{t}}\right) \eta\right)\right) \log [k-\eta]^{2}+2(k-\eta) \log [k-\eta]\left(1+\mathrm{N}_{\mathrm{d}}-2\left(1+\mathrm{N}_{\mathrm{d}}\right) \eta-k\left(\mathrm{~N}_{\mathrm{b}}+\mathrm{N}_{\mathrm{t}}\right)(1+\eta)\right. \\
& \left.+\left(\mathrm{N}_{\mathrm{b}}+\mathrm{N}_{\mathrm{t}}\right) \eta(k+\eta) \log [k+\eta]\right)+(k+\eta) \log [k+\eta]\left(-2\left(k\left(\mathrm{~N}_{\mathrm{b}}+\mathrm{N}_{\mathrm{t}}\right)(1+\eta)\right.\right. \\
& \left.\left.\left.+\left(1+\mathrm{N}_{\mathrm{d}}\right)(-1+2 \eta)\right)+\left(2 k\left(1+\mathrm{N}_{\mathrm{d}}-k\left(\mathrm{~N}_{\mathrm{b}}+\mathrm{N}_{\mathrm{t}}\right)\right)-k\left(\mathrm{~N}_{\mathrm{b}}+\mathrm{N}_{\mathrm{t}}\right) \eta+\left(\mathrm{N}_{\mathrm{b}}+\mathrm{N}_{\mathrm{t}}\right) \eta^{2}\right) \log [k+\eta]\right)\right), \\
& C_{4}=\frac{1}{4 \eta^{2}} \quad\left(2 \eta\left(k\left(\mathrm{~N}_{\mathrm{b}}+\mathrm{N}_{\mathrm{t}}\right)(1+\eta)+\left(1+\mathrm{N}_{\mathrm{d}}\right)(-1+2 \eta)\right)-k\left(-1-\mathrm{N}_{\mathrm{d}}+\left(\mathrm{N}_{\mathrm{b}}+\mathrm{N}_{\mathrm{t}}\right)(k-\eta)\right)(k\right. \\
& -\eta) \log [k-\eta]^{2}+(k-\eta) \log [k-\eta]\left(-1-\mathrm{N}_{\mathrm{d}}-k\left(\mathrm{~N}_{\mathrm{b}}+\mathrm{N}_{\mathrm{t}}\right)(-1+\eta)+4 \mathrm{~N}_{\mathrm{d}} \eta\right. \\
& \left.-\eta\left(-4+\mathrm{N}_{\mathrm{b}}+\mathrm{N}_{\mathrm{t}}+\left(\mathrm{N}_{\mathrm{b}}+\mathrm{N}_{\mathrm{t}}\right) \eta\right)+2\left(-1-\mathrm{N}_{\mathrm{d}}+k\left(\mathrm{~N}_{\mathrm{b}}+\mathrm{N}_{\mathrm{t}}\right)\right)(k+\eta) \log [k+\eta]\right) \\
& +(k+\eta) \log [k+\eta]\left(1+\mathrm{N}_{\mathrm{d}}+k\left(\mathrm{~N}_{\mathrm{b}}+\mathrm{N}_{\mathrm{t}}\right)(-1+\eta)-4 \mathrm{~N}_{\mathrm{d}} \eta-\eta\left(4+\mathrm{N}_{\mathrm{b}}+\mathrm{N}_{\mathrm{t}}+\left(\mathrm{N}_{\mathrm{b}}+\mathrm{N}_{\mathrm{t}}\right) \eta\right)\right. \\
& \left.\left.-k\left(-1-\mathrm{N}_{\mathrm{d}}+\left(\mathrm{N}_{\mathrm{b}}+\mathrm{N}_{\mathrm{t}}\right)(k+\eta)\right) \log [k+\eta]\right)\right) \text {, } \\
& C_{5}=\frac{1}{4 N_{b} \eta} \quad\left(( \mathrm { N } _ { \mathrm { b } } + \mathrm { N } _ { \mathrm { t } } ) \left(2 k(-1+2 \eta)+(1+2 k-2 \eta)(k-\eta) \log [k-\eta]+k(-k+\eta) \log [k-\eta]^{2}\right.\right. \\
& +(k+\eta) \log [k+\eta](1-2 k-2 \eta+k \log [k+\eta])), \\
& C_{6}=\frac{1}{4 \mathrm{~N}_{b} \eta^{2}} \quad\left(( \mathrm { N } _ { \mathrm { b } } + \mathrm { N } _ { \mathrm { t } } ) \left(2 \eta(-1+2 \eta)+k(k-\eta) \log [k-\eta]^{2}+(k+\eta) \log [k+\eta](1-4 \eta+k \log [k+\eta])\right.\right. \\
& -(k-\eta) \log [k-\eta](1-4 \eta+2(k+\eta) \log [k+\eta]))) \text {, } \\
& C_{7}=\frac{1}{4 \eta} \quad\left(( 1 + \mathrm { L } _ { \mathrm { d } } ) \left(2 k(-1+2 \eta)+(1+2 k-2 \eta)(k-\eta) \log [k-\eta]+k(-k+\eta) \log [k-\eta]^{2}\right.\right. \\
& +(k+\eta) \log [k+\eta](1-2 k-2 \eta+k \log [k+\eta]))), \\
& C_{8}=\frac{1}{4 \eta^{2}} \quad\left(( 1 + \mathrm { L } _ { \mathrm { d } } ) \left(2 \eta(-1+2 \eta)+k(k-\eta) \log [k-\eta]^{2}+(k+\eta) \log [k+\eta](1-4 \eta+k \log [k+\eta])\right.\right. \\
& -(k-\eta) \log [k-\eta](1-4 \eta+2(k+\eta) \log [k+\eta]))) \text {. }
\end{aligned}
$$

\section{References}

1. Xiao, B.; Wang, W.; Zhang, X.; Long, G.; Fan, J.; Chen, H.; Deng, L. A novel fractal solution for permeability and Kozeny-Carman constant of fibrous porous media made up of solid particles and porous fibers. Powder Technol. 2019, 349, 92-98. [CrossRef]

2. Xiao, B.; Zhang, X.; Giang, G.; Long, G.; Wang, W.; Zhang, Y.; Liu, G. Kozeny-Carman Constant For Gas Flow Through Fibrous Porous Media By Fractal-Monte Carlo Simulations. Fractals 2019, 27, 1950062. [CrossRef]

3. Liang, M.; Liu, Y.; Xiao, B.; Yang, S.; Wang, Z.; Han, H. An analytical model for the transverse permeability of gas diffusion layer with electrical double layer effects in proton exchange membrane fuel cells. Int. J. Hydrog. Energy 2018, 43, 17880-17888. [CrossRef] 
4. Choi, S.U.S. Enhancing Thermal Conductivity of Fluids with Nanoparticles. In Proceedings of the ASME International Mechanical Engineering Congress and Exposition, Washington, DC, USA, 12-17 November 1995; Volume 66, pp. 99-105.

5. Safaei, M.R.; Togun, H.; Vafai, K.; Kazi, S.N.; Badarudin, A. Investigation of Heat Transfer Enhancement in a Forward-Facing Contracting Channel Using FMWCNT Nanofluids. Numer. Heat Transf. Part A Appl. 2014, 66, 1321-1340. [CrossRef]

6. Zeeshan, A.; Ellahi, R.; Mabood, F.; Hussain, F. Numerical study on bi-phase coupled stress fluid in the presence of Hafnium and metallic nanoparticles over an inclined plane. Int. J. Numer. Methods Heat Fluid Flow 2019, 2854-2869. [CrossRef]

7. Ibrahim, W.; Makinde, O.D. Double-diffusive mixed convection and MHD stagnation point flow of nanofluid over a stretching sheet. J. Nanofluids 2015, 4, 1-10. [CrossRef]

8. Maskeen, M.M.; Zeeshan, A.; Mehmood, O.U.; Hassan, M. Heat transfer enhancement in hydromagnetic alumina-copper/water hybrid nanofluid flow over a stretching cylinder. J. Therm. Anal. Calorim. 2019, 138, 1127-1136. [CrossRef]

9. Ellahi, R. The effects of MHD and temperature dependent viscosity on the flow of non-Newtonian nanofluid in a pipe: Analytical solutions. Appl. Math. Model. 2013, 37, 1451-1467. [CrossRef]

10. Abd Elnaby, M.A.; Haroun, M.H. A new model for study the effect of wall properties on peristaltic transport of a viscous flui. Commun. Nonlinear Sci. Numer. Simul. 2008, 13, 752-762. [CrossRef]

11. Mittra, T.K.; Prasad, S.N. On the influence of wall properties and Poiseuille flow in peristalsis. J. Boimech. 2018, 6, 81-693. [CrossRef]

12. Srivastava, V.P.; Srivastava, L.M. Influence of wall elasticity and poiseuille flow induced by peristaltic induced flow of a particle-fluid mixture. Int. J. Eng. Sci. 1997, 35, 799-825. [CrossRef]

13. Muthu, P.; Kumar, B.V.R.; Chandra, P. Peristaltic motion of micropolar fluid in circular cylindrical tubes: Effect of wall properties. Appl. Math. Model. 2008, 32, 2019-2033. [CrossRef]

14. Nadeem, S.; Maraj, E.N.; Akbar, N.S. Investigation of peristaltic flow of Williamson nanofluid in a curved channel with compliant walls. Appl. Nanosci. 2014, 4, 511. [CrossRef]

15. Hassan, M.; Marin, M.; Alsharif, A.; Ellahi, R. Convective heat transfer flow of nanofluid in a porous medium over wavy surface. Phys. Lett. A 2018, 382, 2749-2753. [CrossRef]

16. Ellahi, R.; Zeeshan, A.; Hussain, F.; Asadollahi, A. Peristaltic blood flow of couple stress fluid suspended with nanoparticles under the influence of chemical reaction and activation energy. Symmetry 2019, 11, 276. [CrossRef]

17. Riaz, A.; Alolaiyan, H.; Razaq, A. Convective Heat Transfer and Magnetohydrodynamics across a Peristaltic Channel Coated with Nonlinear Nanofluid. Coatings 2019, 9, 816. [CrossRef]

18. Bég, O.A.; Tripathi, D. Mathematica simulation of peristaltic pumping with double-diffusive convection in nanofluids: A bio-nano-engineering model. J. Nanoeng. Nanosyst. 2011, 225, 99-114.

19. Akbar, N.S.; Maraj, E.N.; Butt, A.W. Copper nanoparticles impinging on a curved channel with compliant walls and peristalsis. Eur. Phys. J. Plus 2014, 129, 183. [CrossRef]

20. Bhatti, M.M.; Rashidi, M.M. Effects of thermo-diffusion and thermal radiation on Williamson nanofluid over a porous shrinking/stretching sheet. J. Mol. Liq. 2016, 221, 567-573. [CrossRef]

21. Kuznetsov, A.V.; Nield, D.A. Double-diffusive natural convective boundary-layer flow of a nanofluid past a vertical plate. Int. J. Therm. Sci. 2011, 50, 712-717. [CrossRef]

22. Akbar, N.; Khan, Z.; Nadeem, S.; Khan, W. Double-diffusive natural convective boundary-layer flow of a nanofluid over a stretching sheet with magnetic field. Int. J. Numer. Methods Heat Fluid Flow 2016, 26, 108-121. [CrossRef]

23. Akram, S.; Zafar, M.; Nadeem, S. Peristaltic transport of a Jeffrey fluid with double-diffusive convection in nanofluids in the presence of inclined magnetic field. Int. J. Geom. Methods Mod. Phys. 2018, 15, 1850181. [CrossRef]

24. Akbar, N.S.; Habib, M.B. Peristaltic pumping with double diffusive natural convective nanofluid in a lopsided channel with accounting thermophoresis and Brownian moment. Microsyst. Technol. 2019, $25,1217$. [CrossRef]

25. Hayat, T.; Hina, S.; Awatif, A.H.; Asghar, S. Effect of wall properties on the peristaltic flow of a third grade fluid in a curved channel with heat and mass transfer. Int. J. Heat Mass Transf. 2011, 54, 5126-5136. [CrossRef] 
26. Abbas, A.; Bai, Y.; Rashidi, M.M.; Bhatti, M.M. Analysis of Entropy Generation in the Flow of Peristaltic Nanofluids in Channels With Compliant Walls. Entropy 2016, 18, 90. [CrossRef]

27. Srinivas, S.; Kothandapani, M. The influence of heat and mass transfer on MHD peristaltic flow through a porous space with compliant walls. Appl. Math. Comput. 2009, 213, 197-208. [CrossRef]

28. Bhatti, M.M.; Ellahi, R.; Zeeshan, A. Study of Variable Magnetic Field on The Peristaltic Flow of Jeffrey Fluid in A Non-Uniform Rectangular Duct Having Compliant Walls. J. Mol. Liq. 2016, 222, 101-108. [CrossRef]

29. Bhatti, M.M.; Ellahi, R.; Zeeshan, A.; Marin, M.; Ijaz, N. Numerical study of heat transfer and Hall current impact on peristaltic propulsion of particle-fluid suspension with compliant wall properties. Mod. Phys. Lett. B 2019, 33, 1950439. [CrossRef]

30. He, J.H. Homotopy perturbation method for solving boundary value problems. Phys. Lett. A 2006, 350, 87-88. [CrossRef]

(C) 2020 by the authors. Licensee MDPI, Basel, Switzerland. This article is an open access article distributed under the terms and conditions of the Creative Commons Attribution (CC BY) license (http://creativecommons.org/licenses/by/4.0/). 